\title{
Dissociation of cyclopropanone molecule and ion
}

\author{
Jin-Yu Cui* \\ Department of Electrical Engineering, Suihua University, Suihua 152061 China
}

Received 31 October 2013; Accepted (in revised version) 2 January 2014

Published Online 28 February 2014

PACS: 07.77.Gx

\begin{abstract}
Investigate the dissociation and ionization process of cyclopropanone molecules by using the Density functional method. Find the transition states of cyclopropanone molecule and ion, and get the products from transition state to isomer. In the same time, calculate frequency and energy. Confirm their transition states between the reactants and resultants through the Intrinsic Reaction Coordinates (IRC) calculation.
\end{abstract}

Key words: density functional theory, cyclopropanone molecule, dissociation, onization

\section{Introduction}

Ketene is the main component of antimicrobial agents. The study on the properties of cyclopropanone is beneficial to refine new drug ingredients. Cyclopropanone compound is very unstable and research reports about cyclopropanone are not so many at domestic and abroad. As early as 1966, cyclopropanone was formed successfully by Hammond and DeBoer [1, 2] using ketene and diazomethane in Fluorine chloroform. In 2007, Ai et al. [3] reported that cyclopropanone could reach the excited states S1 in $292 \sim 365 \mathrm{~nm}$ wavelength light then $\alpha \mathrm{C}-\mathrm{C}$ bond broke up. There is an intersection (TS1) between the ground state and first excited state on the fragmentation pathway of $\alpha \mathrm{C}-\mathrm{C}$ bond. Then another $\mathrm{C}-\mathrm{C}$ bond broke up and produced carbon monoxide and ethylene. Those are based on quantum chemical method using CASSCF B3LYP and MP2 in theoretically and experimentally. The report is described by the change of bond length and bond angle. And the reported results also provide some clues and bases on the further theoretical and experimental work on the dissociation of cyclopropanone molecule and ion.

In this paper, both cyclopropanone molecule and ion are described [4,5]. We try to find the characteristics of the cyclopropanone molecule and ion by investigating the dissociation process. Some helpful information can be obtained, including the disabled

${ }^{*}$ Corresponding author. Email address: cjy8103181@126. com (J. -Y. Cui ) 
process of cyclopropanone molecule and ion from its potential energy surface. Therefore, it is significant for us to work on the dissociation of potential energy surface. Here, two possible dissociation paths on molecule are reported. One possible dissociation path is that the $2 \mathrm{C}-4 \mathrm{C}$ single bond breaks up and forms an open-loop structure, then another $2 \mathrm{C}-3 \mathrm{C}$ bond breaks up and produces $\mathrm{CO}$ and $\mathrm{C}_{2} \mathrm{H}_{4}$. The other is that $3 \mathrm{C}-4 \mathrm{C}$ bond breaks up and forms isomer, then dissociates $\mathrm{C}_{2} \mathrm{H}_{2} \mathrm{O}$ and $\mathrm{CH}_{2}$. It is found that the configuration of the cyclopropanone ion is unstable, and the open-loop structure of stable ion configurations is got.

\section{Basic theory and computational methods}

Quantum mechanics theory is the basic theory in microscopic field, in which all phenomena can be explained with knowledges of quantum mechanics. Therefore, we use modern methods of quantum chemistry and atomic molecular theory to study the molecular problems [6]. Density functional theory is a powerful computational tool to calculate the larger molecules systems. Compared with Hartree-Fock (HF) and Moller-Plesset (MP), it can save much time. In this work, geometrical parameters of the reactants, products, intermediates, and transition states are optimized basing on the unrestricted B3LYP [7] with the 6-31 + G (d, p) basis set from density functional theory (DFT). Harmonic vibration frequencies that are calculated at the same level are used for the characterization of stationary points. Meanwhile, according to further analysis by IRC calculations [8-10], the transition states are between reactants and products. All calculations are performed using GAUSSIAN 03 programs.

\section{Results and discussion}

Cyclopropanone formula is $\mathrm{C}_{3} \mathrm{H}_{4} \mathrm{O}$. By optimizing structures and correcting correlation energies of the molecule, the energy is -191. 8966 Hartree, and there is no imaginary frequency. The optimized geometry of stationary point has been plotted in Fig. 1. The vibration frequencies and the relative intensities are listed in Table 1 and showed in Fig. 1. There are many vibrational modes around the vibration peaks. From Table 1, the maximum vibration intensity of $358.371 \mathrm{KM} /$ Mole occurs at the frequency of 1930.79 $\mathrm{cm}^{-1}$, its intensity is $108.244 \mathrm{KM} /$ Mole at the frequency of $964.151 \mathrm{~cm}^{-1}$, and its intensity is $27 \mathrm{KM}$ /Mole at the frequency of $1018.02 \mathrm{~cm}^{-1}$. In addition, its intensity is $15 \mathrm{KM} / \mathrm{Mole}$ at the frequency of $1072.33 \mathrm{~cm}^{-1}$. Analysis on a few frequencies is given as follows while other modes are neglected.

First, from Table 1, at the frequency of $1930.79 \mathrm{~cm}^{-1}$ and intensity of $358.371 \mathrm{KM} /$ Mole, $1 \mathrm{O}$ atom and $2 \mathrm{C}$ atoms have the strongest vibration. It should make $2 \mathrm{C}-3 \mathrm{C}$ bond or $2 \mathrm{C}$ $-4 \mathrm{C}$ bond break up, forming the products of $\mathrm{CO}$ and $\mathrm{C}_{2} \mathrm{H}_{4}$, or it may make $\mathrm{O}-2 \mathrm{C}$ bond break up, forming $\mathrm{O}$ and $\mathrm{C}_{3} \mathrm{H}_{4}$. However, transition states of these two dissociations are not found [11], which shows they are difficult to happen! So it is possible that it makes 


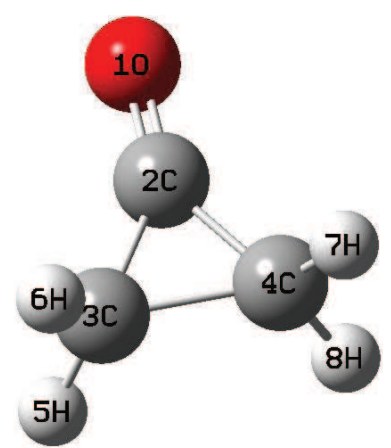

(a) Geometry

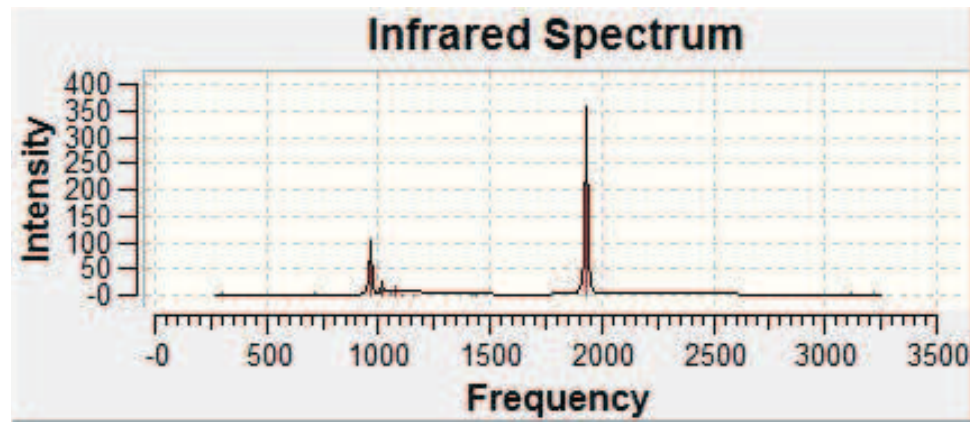

(b) Infrared Spectrum

Figure 1: Geometry and infrared Spectrum of cyclopropanone molecule.

Table 1: Frequency and Intensity of cyclopropanone molecule.

\begin{tabular}{ccc|ccc}
\hline No. & Frequency $\left(\mathrm{cm}^{-1}\right)$ & Intensity(KM/Mole) & No. & Frequency $\left(\mathrm{cm}^{-1}\right)$ & Intensity(KM/Mole) \\
\hline 1 & 302.538 & 5.8293 & 2 & 499.134 & 1.8088 \\
3 & 648.857 & 0.0002 & 4 & 705.332 & 1.5269 \\
5 & 715.641 & 4.0415 & 6 & 964.151 & 108.244 \\
7 & 1018.02 & 27.3951 & 8 & 1056.58 & 5.1342 \\
9 & 1072.33 & 15.0874 & 10 & 1106.07 & 0.31 \\
11 & 1160.62 & 0.0003 & 12 & 1422.06 & 6.2715 \\
13 & 1440.87 & 4.2192 & 14 & 1930.79 & 358.371 \\
15 & 3121.69 & 3.1641 & 16 & 3122.03 & 1.0457 \\
17 & 3201.66 & 0.0001 & 18 & 3213.59 & 2.3383 \\
\hline
\end{tabular}

a single bond $(2 \mathrm{C}-3 \mathrm{C})$ break up, forming the open-loop structure of isomers, and then makes the other bond $(2 \mathrm{C}-4 \mathrm{C})$ break up to form $\mathrm{CO}$ and $\mathrm{C}_{2} \mathrm{H}_{4}$. This dissociation path has been plotted in Fig. 2 .

Second, from Table 1, at the frequency of $964.15 \mathrm{~cm}^{-1}$ and intensity $=108.242 \mathrm{KM} /$ Mole, vibration amplitude is relatively large. The result of analyzing its vibration [12] shows that $2 \mathrm{C}$ swings left and right and amplitude of its swing is very large. This may cause 2C- 


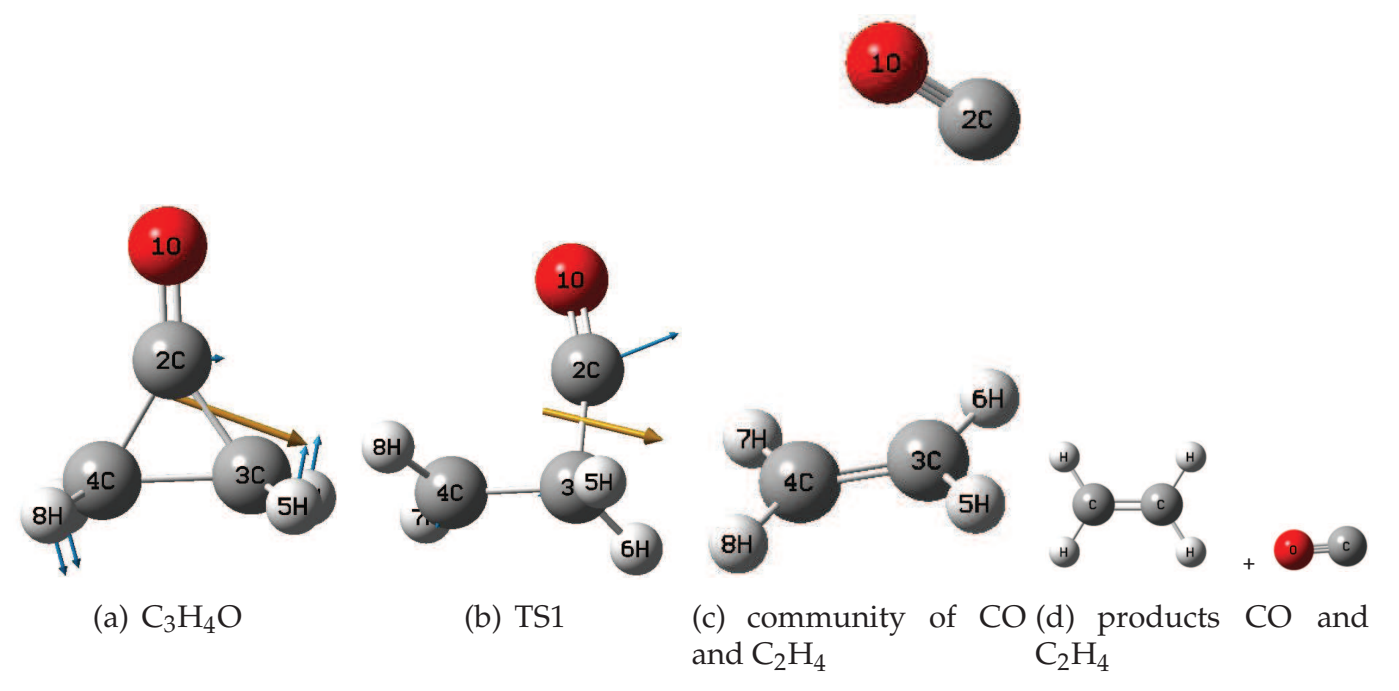

Figure 2: Dissociation of cyclopropanone molecule (1).

$4 \mathrm{C}$ or $2 \mathrm{C}-3 \mathrm{C}$ bond break up, forming the open-loop molecular (cyclopropanone molecular symmetry leading to $2 \mathrm{C}-4 \mathrm{C}$ or $2 \mathrm{C}-3 \mathrm{C}$ bond fracture identical). The transition state [13] TS1 is calculated and obtained, plotted in Fig. 2. Its energy is -191.8350 Hartree, at the only imaginary frequency [14] of $-642.68 \mathrm{~cm}^{-1}$. Vibration mode shows that $2 \mathrm{C}$ vibrates outwardly strongly, which will probably results in the fracture of $2 \mathrm{C}-3 \mathrm{C}$ bond and TS2 being obtained. The results of IRC calculation shows that TS2 can recur a reactant in one direction. At the same time, the optimized results of the other direction can form the community of $\mathrm{CO}$ and $\mathrm{C}_{2} \mathrm{H}_{4}$. But the community is not stable configuration, whose energy is -191.9171 Hartree. Then the community dissociates into products $\mathrm{CO}$ and $\mathrm{C}_{2} \mathrm{H}_{4}$. The process has been plotted in Fig. 2.

Third, from Table 1, at the frequency of $-1018.02 \mathrm{~cm}^{-1}$ and intensity of $27 \mathrm{KM} / \mathrm{Mole}$, vibration modes were also analyzed. $3 \mathrm{C}$ and $4 \mathrm{C}$ vibrate outwards, looking for transition state TS2 of 3C-4C bond fracture, then obtained it. Imaginary frequency of TS2 is $-525.1544 \mathrm{~cm}^{-1}$, and its energy is -191.8287 Hartree. IRC calculation shows that it is the transition state between the reactants and the isomers (INT1). The energy of INT1 is 191.8799 Hartree and its structure is stable. The vibration mode shows that 2C and 3C vibrate violently toward opposite directions, causing $2 \mathrm{C}-3 \mathrm{C}$ bond fracture. Then the transition state TS3 is obtained, whose energy is -191.6539 Hartree and imaginary frequency is $-46.53 \mathrm{~cm}^{-1}$. Eventually, it forms the stable product community of $\mathrm{C}_{2} \mathrm{H}_{2} \mathrm{O}$ and $\mathrm{CH}_{2}$ [15]. However, due to the high barrier of TS3, the molecule dissociates into products $\mathrm{C}_{2} \mathrm{H}_{2} \mathrm{O}$ and $\mathrm{CH}_{2}$ far less easily than that described above.

The optimized geometries of TS2, INT1, TS3 and corresponding products have been plotted in Fig. 3.

Forth, from Table 1, at the frequency of $1072.33 \mathrm{~cm}^{-1}$ and the intensity of $15 \mathrm{KM} /$ Mole, 


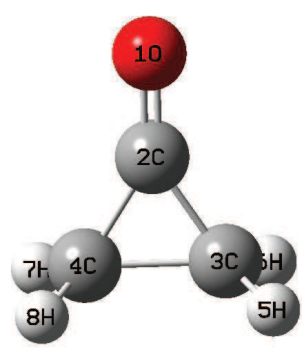

(a) $\mathrm{C}_{3} \mathrm{H}_{4} \mathrm{O}$

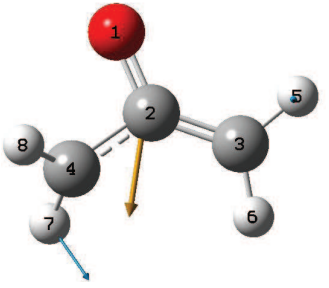

(b) TS2

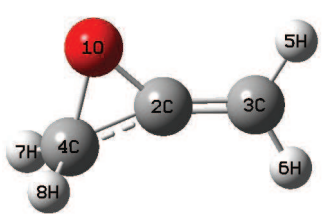

(c) TNT1

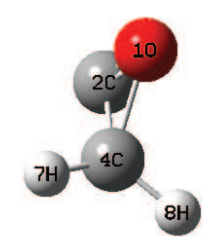

(d) TS3

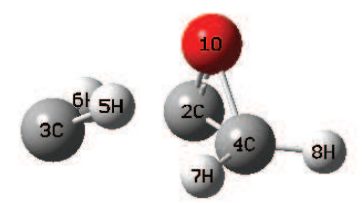

(e) community of $\mathrm{C}_{2} \mathrm{H}_{2} \mathrm{O}$ and

Figure 3: Dissociation of cyclopropanone molecule (2).

vibration directions of $3 \mathrm{C}$ and $4 \mathrm{C}$ are still in reverse, but they are different from what said above. The vibration is not outwards, but is up and down. Molecular will twist, which may cause the fracture of $2 \mathrm{C}-3 \mathrm{C}$ or $2 \mathrm{C}-4 \mathrm{C}$ bond, similar to the second situation, or fracture of $3 \mathrm{C}-4 \mathrm{C}$ bond [16] , the same as the third situation.

\begin{tabular}{|c|c|c|c|c|}
\hline Name & SCF energy (Hartree) & SCF energy $(\mathrm{eV})$ & Contrasting with & $\begin{array}{c}\text { Imaginary frequencies }\left(\mathrm{cm}^{-1}\right) \\
\text { in the reactant ground state }\end{array}$ \\
\hline Reactant $\mathrm{C}_{3} \mathrm{H}_{4} \mathrm{O}$ & -191.8966 & -5221.7751 & 0 & no \\
\hline TS1 & -191.8350 & -5220.0989 & 1.6761 & -642.68 \\
\hline $\mathrm{CO}$ and $\mathrm{C}_{2} \mathrm{H}_{4}$ community & -191.9172 & -5222.3357 & -0.5605 & two values \\
\hline Products $\mathrm{CO}$ and $\mathrm{C}_{2} \mathrm{H}_{4}$ & -191.9169 & -5222.3275 & -0.5524 & no \\
\hline TS2 & -191.8287 & -5219.9274 & 1.8476 & -525.15 \\
\hline INT1 & -191.8799 & -5221.3207 & -0.4543 & no \\
\hline TS3 & -191.6539 & -5215.1709 & 6.6042 & -46.53 \\
\hline $\mathrm{C}_{2} \mathrm{H}_{2} \mathrm{Oand} \mathrm{CH} 2$ community & -191.6542 & -5215.1791 & 5.9984 & no \\
\hline Ion $\mathrm{C}_{3} \mathrm{H}_{4} \mathrm{O}^{+}$(TS4) & -191.5612 & -5212.6484 & 9.1267 & -285.23 \\
\hline INT2INT3 & -191.5798 & -5213.1546 & 8.6205 & no \\
\hline TS5 & -191.5525 & -5212.4117 & 9.3634 & -164.15 \\
\hline
\end{tabular}

The normal coordinate of the stable cyclopropanone molecule is regarded as input to optimize the structure of the ion $[4,5,17]$, resulting in the transition state (TS4). The energy of TS4 is -191.5612 Hartree. It has only one imaginary frequency of $-285.23 \mathrm{~cm}^{-1}$, which indicates cyclopropanone ion is unstable. Then the vibration of the imaginary frequency is observed, both $1 \mathrm{O}$ and $2 \mathrm{C}$ vibrate strongly towards opposite directions, resulting in the rupture of $2 \mathrm{C}-4 \mathrm{C}$ or $2 \mathrm{C}-3 \mathrm{C}$ bond, forming the stable open-loop ions (INT2). They are shown in Fig. 4. The energy of INT2 is -191.5798 Hartree, it has no imaginary frequency 


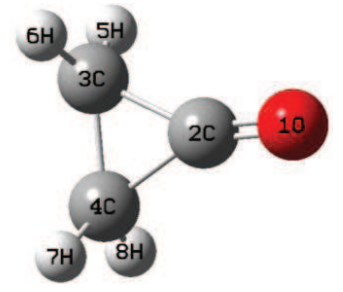

(a) $\mathrm{C}_{3} \mathrm{H}_{4} \mathrm{O}^{+}$

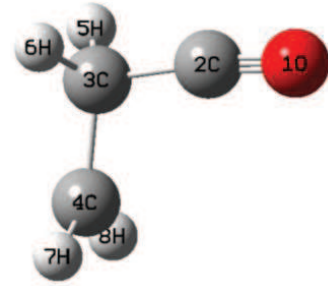

(b) TNT2

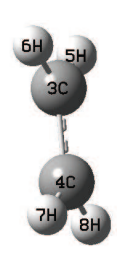

(c) TS5

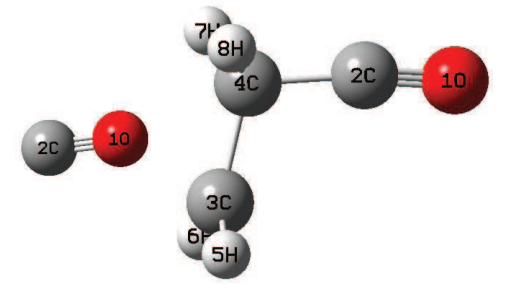

(d) TNT3

Figure 4: Isomerism of cyclopropanone ion.

so it is stable. Gaussion view shows that $1 \mathrm{O}$ and $2 \mathrm{C}$ vibrate outwards. According to further calculation, TS5 is gotten, its imaginary frequency value is $-164.15 \mathrm{~cm}^{-1}$, and its energy is -191.5525 Hartree. The result of IRC calculation shows that TS5 is the transition state between INT2 and INT3. INT2 and INT3 are the geometries of stationary points for the ions. The process has been plotted in Fig. 4.

The dissociation potential energy surfaces are constructed in Fig. 5 and detailed results are listed in Table 2.

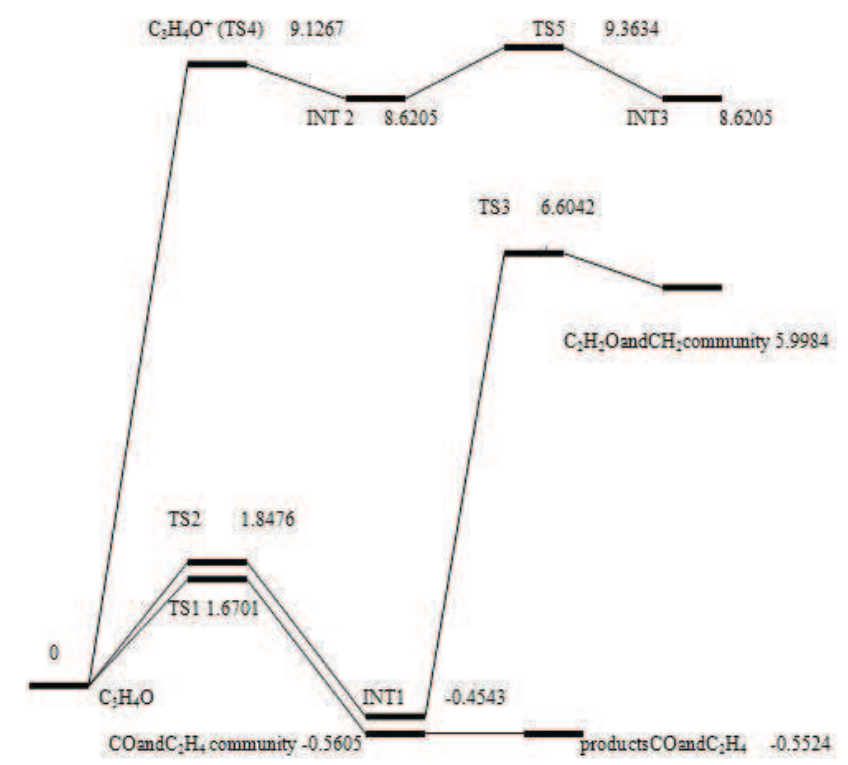

Figure 5: The energies surface of dissociation of cyclopropanone molecule and ion.

\section{Conclusions}

We have investigated three dissociation paths of cyclopropanone molecule and ion. It is found that five transition state structures and three isomeric structures occur during the 
dissociation processes. Based on the calculations and analysis above, we can conclude that cyclopropanone molecule dissociation products is $\mathrm{CO}$ and $\mathrm{C}_{2} \mathrm{H}_{2}$, which are the same results as that of Ai et al. [3]. But there are also $\mathrm{C}_{2} \mathrm{H}_{2} \mathrm{O}$ and $\mathrm{CH}_{2}$ products according to the calculation results.

Although the molecules will form $\mathrm{C}_{2} \mathrm{H}_{2} \mathrm{O}$ and $\mathrm{CH}_{2}$ when they are given enough energy, it is much more difficult to achieve due to higher barrier of TS3 (TS3 $=-191.6539 \mathrm{eV}$ ) than the former (TS1 =-191.8350 eV). In addition, it is easy to fracture the single bond, and it is difficult to fracture the double bonds simultaneously while products are $\mathrm{CO}$ and $\mathrm{C}_{2} \mathrm{H}_{2}$.

The same method is used to cyclopropanone ion $\mathrm{C}_{3} \mathrm{H}_{4} \mathrm{O}^{+}$. It is unstable configuration, which has an imaginary frequency value, and its open-loop structure is stable isomer. The isomerization process is given.

Acknowledgments. This work is supported by Heilongiiang Provincial Department of Education under Grant No. 12521653, and was supported by Science and Technology Ddepartment of Suihua University under Grant No. K1201007.

\section{References}

[1] N. J. Turro and W. B. Hammond, J. Am. Chem. Soc. 87 (1965)3258.

[2] S. E. Schaafsma, H. Steinber, and T. J. Deboer, Rec. Trav. Chim. 85 (1966)1170.

[3] Y. J. Ai, L. Lin, and W. H. Fang, Acta Chim. Sin. 65(2007)129 (in Chinese).

[4] J. Y. Cui, M. X. Jin, Z. G. Wang, et al., J. At. Mol. Phys. 26 (2009)787 (in Chinese).

[5] J. Y. Cui, J. At. Mol. Phys. 27 (2011) 199 (in Chinese).

[6] J. E. Tønder, J. B. Hansen, M. Begtrup, I. Pettersson, K. Rimvall, B. Christensen, U. Ehrbar, and P. H. Olesen, J. Med. Chem. 42 (1999) 4970.

[7] W. M. Mullett, E. P. C. Lai, and B. Sellergren, Anal. Commun. 36 (1999) 217.

[8] A. D. Becke, Chem. Phys. 98 (1993) 56.

[9] C. Lee, W. Yang, and R. G. Parr, Phys. Rev. B 37 (1988) 785.

[10] J. P. Simons, Comments At. Mol. Phys. 16 (1985) 157.

[11] T. Takeshima, R. Fukumoto, T. Egawa, and S. Konaka, J. Phys. Chem. A 106 (2002) 8734.

[12] O. Gunnarssonand R. O. Jones, Phys. Scr.. 21 (1980) 394.

[13] A. Zander, P. Findlay, T. Renner, and B. Sellergren, Anal. Chem. 70 (1998) 3304.

[14] V. Barone, J. Chem. Phys. 120 (2004) 3059.

[15] A. D. Becke, J. Chem. Phys. 98 (1993) 5648.

[16] Z. G. Wang, S. F. Pan, and M. G. Yao, J. Mol. Struct.: Theochem. 767 (2006) 99.

[17] M. X. Jin, Q. L. Cui, E. Mukhtar, et al., J. Phys.: Condens. Matt. 14 (2002) 11037. 